\title{
Retrospectiva
}

\section{Corpora na Tradução}

VIANA, V.; TAGNIN, S. E. O. (org.). Corpora na Tradução. São Paulo: Hub Editorial, 2015. ISBN 978-85-8076-271-6. 331p.

Regiani Aparecida Santos Zacarias*

Nas ciências Humanas e Sociais, os computadores, softwares e os mecanismos operacionais abrem novas perspectivas de estudos e pesquisas, assegurando confiabilidade na busca de informações e na tabulação de resultados. A Linguística de Corpus (LC), estuda o uso da língua por meio da observação de linguagem autêntica (VIANA; TAGNIN, 2010 ,p. 19). Atualmente, grande parte das pesquisas no campo da LC está associada à união da tecnologia à Linguística. É característica marcante da Linguística de Corpus o diálogo com diversas áreas do saber, com o objetivo de contribuir para o desenvolvimento e avanço do conhecimento.

No contexto desta temática, é imprescindível registrar e esclarecer à comunidade acadêmico-científica o escopo da Linguística de Corpus em colaborar com as outras áreas das ciências humanas e sociais. Esta é a principal finalidade do livro Corpora na Tradução, organizado pelos pesquisadores Stella Tagnin e Vander Viana: ela, professora e pesquisadora da Universidade de São Paulo; ele, professor e pesquisador da Universidade de Stirling, na Escócia. Trata-se da primeira obra, em língua portuguesa e publicada no Brasil, que aborda a inter-relação entre a Linguística de Corpus e os Estudos da Tradução e suas práticas, no âmbito de vários pares de línguas. O tema é apresentado de forma clara e objetiva, colaborando, com sucesso,

\footnotetext{
* Doutora em Estudos da Linguagem pela Universidade de Londrina, docente UNESP/Assis e UNESP/Bauru. regiani.zacarias@unesp.br
} 
com a tarefa de consolidar o assunto em nosso país. O livro é composto por 10 artigos e um glossário. Os artigos apresentam as definições terminológicas e as particularidades da LC, os diferentes tipos de Corpora linguísticos e suas funções, bem como, algumas pesquisas que ilustram a utilização desses como instrumentos de pesquisa compilados para a realização de investigações linguísticas (VIANA, 2010). As amostras de pesquisas descritas no livro atribuem o sucesso de seus resultados ao uso de Corpora. Os textos foram redigidos por renomados (as) pesquisadores da Universidade Federal de Santa Catarina, Universidade de São Paulo, Universidade Federal de Uberlândia, Universidade Federal de Minas Gerais, Universidade Federal de Ouro Preto e da Universidade Federal de São Carlos.

O Prefácio foi redigido por João Azenha Júnior que, com o brilhantismo que lhe é característico, destaca a velocidade e a integração como os principais diferenciais proporcionados, pela tecnologia à tradução, em favor da espantosa evolução desta área. $\mathrm{O}$ autor alerta que a união dos Estudos da Tradução à Linguística de Corpus requer mudança de atitude no desenvolvimento da prática tradutória e que, o livro Corpora na Tradução contribui e auxilia na construção da nova práxis.

Na Introdução, os organizadores destacam a relevância da associação das ferramentas tecnológicas ao trabalho de tradução, lembrando que, anteriormente, os dicionários monolíngues e bilíngues eram as únicas ferramentas de apoio a esta minuciosa tarefa. Desse modo, revelam o objetivo principal do livro: “O presente volume enfoca justamente uma das possibilidades que surgiram com a popularização dos computadores pessoais: a investigação de corpora..." (VIANA; TAGNIN, 2015, p. 11). À continuidade, os autores esclarecem o conceito de corpora, suas aplicabilidades, funções que desempenham e a diferença entre a pesquisa em Corpora e as buscas no Google. Por fim, destacam as principais vantagens do uso de Corpora como instrumento de pesquisa e revelam o desejo de inspirar os leitores a conduzirem mais pesquisas na área de tradução, valendo-se de Corpora. 
No capítulo que abre a coletânea, "A Linguística de Corpus na e para a tradução", a autora Stella Tagnin (USP) apresenta as principais características dos corpora e cumpre com êxito a proposta de elucidar o tema ao leitor não especialista. $\mathrm{O}$ texto é desenvolvido de forma didática, apresentando o conceito de corpus, seus diferentes tipos e os objetivos a que se destinam. São demonstrados também os procedimentos de compilação e anotação de corpus e subcorpus, fundamentados nos tipos de pesquisa que atendem. Na sequência, a autora revela as principais ferramentas computacionais que permitem a exploração dos dados de um determinado corpus para um fim específico, como por exemplo, a elaboração de uma lista de termos para encontrar as palavras mais frequentes em uma coletânea de textos jornalísticos ou em uma obra específica. Ao final, Stella Tagnin estimula o leitor a apoiar-se no uso de corpora em suas pesquisas. Para tanto, recorre à apresentação de trabalhos realizados com sucesso e que, sem o auxílio de Corpora, talvez não tivessem alcançado resultados satisfatórios.

O segundo artigo, "Teses e Dissertações sobre Tradução e Linguística de Corpus: um panorama da produção científica brasileira", escrito por Caroline Reis Vieira Santos (UFSC), apresenta os resultados de uma pesquisa que coletou as dissertações e as teses, realizadas no Brasil, referentes à temática corpus e tradução. Por meio de busca no Portal da Capes, a autora avaliou 112 trabalhos entre 1998 e 2011; as análises das pesquisas seguiram os seguintes critérios: nível de ensino (mestrado ou doutorado) e IES (Instituição de Ensino Superior); grande área, área e subárea do conhecimento; programa usado na análise de corpora e atributos dos corpora usados nas pesquisas. A título de exemplificação, os resultados revelam que foram encontradas 82 dissertações e 30 teses realizadas em 12 instituições diferentes. Observou-se também que 2007 foi o ano com o maior número de trabalhos defendidos - em geral, a Linguística Aplicada foi apontada como grande área, e WordSmith Tools (WST) a ferramenta mais utilizada. A autora conclui que são necessárias novas e mais 
aprofundadas investigações sobre o tema. O artigo contribui de forma significativa para comprovar a solidez do assunto no ambiente acadêmico-científico brasileiro.

O foco do terceiro artigo é "A busca por equivalentes para termos culturalmente marcados: o caso da farinha de milho". Nele são relatados os procedimentos e resultados da pesquisa desenvolvida por Rozane R. Rebechi (USP), que apresenta a análise semiautomática como alternativa para solucionar desambiguações. O procedimento consiste em buscar palavras em textos autênticos organizados em um corpus compilado para estudo específico. A autora descreve os detalhes da metodologia utilizada e afirma que a metodologia baseada na análise de corpus ajuda na identificação de equivalentes tradutórios adequados em língua inglesa. A pesquisa destacou que, embora o número de publicações de traduções de receitas culinárias típicas do Brasil para a língua inglesa tenha crescido, é evidente a falta de equivalentes padronizados. Diante da impossibilidade de se encontrar equivalentes satisfatórios e consistentes em dicionários, corre-se o risco de descaracterização dos marcadores culturais da culinária brasileira. O corpus comparável formado por textos autênticos e suas respectivas traduções permitem a análise contextualizada dos termos tendo como resultado a precisão da associação léxico-semântica em ambas as línguas. O texto evidencia que a metodologia baseada na Linguística de Corpus pode ser uma boa opção na busca pela padronização de equivalentes com marcas culturais.

O quarto capítulo, escrito por Helmara Febeliana Real Moraes (USP), tem por título “A questão da Equivalência entre os advérbios em -ly e -mente no par de línguas inglês-português: como funciona em línguas de especializadas"? A autora teve como objetivo verificar se os advérbios com terminação -ly em inglês possuem correspondência em advérbios terminados em -mente em português. A pesquisa apresentada analisou corpora comparáveis compilados por pesquisadores do projeto CoMET nos temas receitas culinárias e contratos (Direito). Moraes aponta em 'materiais e métodos' todas as etapas realizadas para a compilação e análise dos 
corpora. A pesquisadora esclarece que foram selecionados cinco advérbios para análise considerando-se aqueles de maior chavicidade em cada área. As linhas de concordância da tradução 'prima face' dos mesmos também foram investigadas. Na sequência foi realizada a busca da palavra em unidades fraseológicas para identificar aquelas em que o advérbio co-ocorria em inglês e em português. $\mathrm{O}$ artigo revela que o uso de corpora comparáveis foi determinante para a análise dos advérbios em contextos específicos.

Guilherme Fromm (UFU) e Flávia Santos da Silva (UFU) são autores do quinto capítulo ‘Neologismo e modalidades de tradução em um corpus de ficção científica'. Este capítulo enfoca a análise do gênero ficção científica, tendo como objeto de estudo as legendas produzidas por tradutores alternativos para o seriado australiano Farscape. A pesquisa faz uma análise trilíngue em inglês, português e espanhol, na ênfase dos termos técnicos e do vocabulário de especialidade relacionados às áreas Astronomia, Astronáutica, Astrofísica. A revisão da literatura fundamentou-se nos conhecimentos sobre Terminologia e Linguística de Corpus (FROMM, 2011), neologismos fonológicos (ALVES, 1990), Tradução (AUBER, 1998) e nos estudos sobre Teoria Comunicativa de Terminologia (KRIEGER; FINNATTO, 2004). O trabalho apresenta dados estatísticos coletados em um corpus especialmente compilado para a pesquisa e que salienta vocabulários de especialidade relacionados às áreas contempladas. O trabalho de análise de traduções não profissionais já é por si inovador e a sua associação com a Linguística de Corpus torna-o ainda mais interessante. Claro, objetivo e valendo-se de termos como Charrid, Masata, Toubray, Mivonks, dentre outros, o texto revela que os empréstimos e decalques são as modalidades de traduções mais usadas por tradutores não profissionais.

O capítulo seis "Quando seus olhos fogem do assunto": uma análise de corpus compilado com as combinações criativas na obra literária de Chico Buarque" de autoria de Sérgio Marra de Aguiar (UFU), propõe verificar empiricamente, por meio 
de uma análise descritiva, até que ponto as combinações lexicais não usuais criadas por Chico Buarque de Holanda nas obras Estorvo, Benjamin e Budapeste foram ou não recuperadas na tradução para o inglês. $\mathrm{O}$ estudo recorreu a um corpus paralelo com o objetivo de descrever e de analisar as escolhas feitas pelos tradutores para algumas combinações menos convencionais envolvendo a palavra 'olhos'. A análise revela detalhes do processo de tradução e destaca a preocupação em manter a exuberância linguística da obra, fruto da riqueza do labor linguístico e das expressões inusitadas criadas pelo autor. O trabalho apresenta os detalhes do fazer tradutório das obras de Buarque e revela que houve empenho por parte dos tradutores com o propósito de recuperar as intenções do autor. O resultado comprova o sucesso do trabalho de tradução para o inglês e exalta o talento do escritor ao servir-se da língua portuguesa. Desse modo, incentiva o leitor a ler as versões originais, em português, dos livros, bem como suas respectivas traduções. O artigo é, certamente, referencial da aplicação da Linguística de Corpus às pesquisas literárias.

O sétimo capítulo, escrito por Célia M. Magalhães e Taís P. Blauth, ambas da UFMG, intitula-se "Estilo do Tradutor: um estudo do uso do itálico, palavras estrangeiras e itens culturais específicos por seis tradutores do português de Heart of Darkness. O estudo propõe uma abordagem mista em que há a análise do estilo do tradutor e também do estilo da tradução em busca de respostas às seguintes perguntas: há prominência de uso do itálico, palavras estrangeiras e itens culturais específicos nas traduções analisadas? Tal uso pode ser atribuído ao estilo do autor do texto original, a convenções de uso da língua portuguesa para o texto literário, à hipótese da retradução, ou ao estilo da tradução e/ou do tradutor? O trabalho foi realizado a partir de um corpus específico composto pela obra original em inglês e pelas seis traduções em línguas portuguesa. Ao longo do capítulo, as autoras apresentam os dados quantitativos em tabelas e os dados qualitativos por meio de exemplos que levam à compreensão dos resultados obtidos. Esses fatores ainda revelam traços comuns a 
todas as traduções em língua portuguesa e outros específicos de um ou de mais textos traduzidos. É relevante destacar o valor da pesquisa, não apenas por responder às questões propostas, mas também pelo fato de atestar a relevância da Linguística de Corpus ao processo metodológico de pesquisas que tratam da estilística tradutória.

O oitavo capítulo, "Equivalência em foco: padrões na tradução para a língua inglesa de significados existenciais do português brasileiro", trata do uso de corpora paralelos para estudos relacionados aos padrões em tradução e ao estabelecimento de equivalências tradutórias. O foco de comparação são as orações existenciais, com base na Teoria da Linguística Sistêmico-Funcional (LSF). Para o exame da equivalência tradutória, o estudo adota a perspectiva da tipologia de contrastes de equivalente que consiste em mapear quais escolhas, dentre as disponíveis na língua-alvo, para a tradução de um dado item numa língua-fonte, são feitas e o que as frequências revelam sobre possíveis padrões na relação tradutória entre dois sistemas linguísticos. O corpus de estudo compreende textos em português e em inglês, com textos originais e traduzidos nessas duas línguas. Na análise, os pesquisadores observaram de que forma significados existenciais em português, que podem ser expressos por verbos como 'haver', 'ser', 'ter', 'vir', entre outros, são ressignificados em língua inglesa. Os resultados obtidos revelam, como relatam os autores, o uso de corpus paralelo como fonte inestimável de dados que podem contribuir para a continuidade do estudo ora apresentado.

No nono capítulo “Tradução automática: O uso de corpora paralelos para a criação de um tradutor automático estatístico", por Helena de M. Caseli (UFSCar) a autora introduz o leitor à tradução automática e descreve como os corpora paralelos são usados no treinamento de um tradutor automático estatístico baseado em frases, considerando-se o que há de mais moderno em sistemas de tradução automática. Uma das considerações levantadas no texto é que, embora este tipo de tradução apresente 
limitações, traz as vantagens de uso em larga escala, devido ao baixo custo de sua geração e de aplicação em relação a praticamente qualquer par de línguas.

O décimo capítulo, escrito pelo professor Vander Viana (Universidade de Stirling, Escócia) apresenta uma lista de corpora disponíveis on-line que abarcam uma diversidade de línguas. O objetivo do texto é auxiliar o tradutor/pesquisador que deseja identificar um corpus adequado aos objetivos de sua pesquisa. Cada corpus é identificado com uma ficha contendo as seguintes informações: (1) nome e respectiva sigla; (2) breve definição com eventuais referências cruzadas para outras entradas; (3) comentário conciso a respeito de publicações que o tomaram como recurso e/ou que relatam estudos dele decorrentes e (4) o endereço eletrônico para acesso ao recurso descrito. Há também um índice organizado por línguas e sublínguas que facilita a consulta aos 100 verbetes. As informações contidas neste capítulo são congruentes ao conteúdo da obra. O capítulo realiza com excelência o fechamento do livro, uma vez que, face ao conhecimento apresentado nos capítulos anteriores, oferece ao leitor incentivo e orientações para 'colocar a mão na massa'!

O livro apresenta, ainda, em sua parte final, um glossário de linguística de corpus com 53 termos, redigido por Stella E. O. Tagnin (USP). O glossário apresentase como um referencial que registra que ajuda na compreensão dos estudos e pesquisas em Linguística de Corpus.

Este é o segundo livro organizado por Vander Vianna e Stella Tagnin que aborda Corpora linguísticos como tema central, o primeiro livro foi Corpora no Ensino de Línguas. A consolidação da Linguística de Corpus como importante ferramenta de pesquisa aliada aos estudos de tradução é assunto recente, fato que justifica a importância desta obra que reúne estudos relacionados ao uso de Corpora Linguísticos em vários idiomas e que se destina ao leitor não especialista em busca de conhecimento sobre o tema. 
No âmbito da tradução, o procedimento de digitalização de textos e as compilações de Corpora e de coletâneas em bancos de dados trouxeram autonomia, confiabilidade e adequabilidade ao desempenho de tarefas e ao alcance de resultados. Registrar, esclarecer e divulgar a Linguística de Corpus, em especial, na área da tradução é uma iniciativa imprescindível e louvável no momento. Certamente, recomenda-se que sejam realizadas leituras de outras obras para se conhecer outras vertentes do assunto. No entanto, face aos comentários apresentados, recomenda-se a leitura do livro Corpora na Tradução àqueles que desejam inteirar-se do assunto ou conhecer mais sobre o tema.

\section{Referência}

LABOV, W. Principles of Linguistic Change. Massachusetts/Oxford: Blackwell, 2001. 